\title{
Research of working capacity of pulsed variable-speed drives
}

\author{
Oleg Sharkov ${ }^{1, *}$, Sergey Koryagin ${ }^{1}$, and Nikolay Velikanov ${ }^{1}$ \\ ${ }^{1}$ Immanuel Kant Baltic Federal University, Institute of Engineering and Technology, 236016 Kaliningrad, Russia
}

\begin{abstract}
The paper presents the results of experimental researches of the basic working capacity characteristics of pulsed variable-speed drives - gear ratio, efficiency factor, and reliability of the eccentric free-wheel mechanisms When conducting research, the main working capacity parameters of the pulsed variable-speed drive (independent factors) changed according to the design of experiment in the range: the load applied to the output shaft was from 250 to $2.750 \mathrm{~N} \cdot \mathrm{m}$; adjustable gear ratio - from 20 to 180 . It was established that the reliability of the eccentric free-wheel mechanisms is guaranteed when making mechanisms of $100 \mathrm{Cr} 6$ steel with hardness not lower than $\mathrm{HRC}_{\ni} 58 \ldots 62$ with a module of at least $0.75 \mathrm{~mm}$. It was shown that the yield surface, which characterizes the change in the gear ratio of the pulsed variablespeed drive, can be described by a model using first-order polynomials. It was established that with increasing load, a slight increase (at 1.0...9.9\%) occurs in the adjusted gear ratio, which has a character close to linear. It was concluded that with an increase in load, the increase in efficiency factor is non-linear and equals 1.8...2.6 times, an increase in the gear ratio causes its linear decrease by 1.13...1.64 times in the dependence close to a linear one. Empirical dependences are obtained to determine the magnitude of the gear ratio and efficiency factor.
\end{abstract}

\section{Introduction}

In modern machines, along with the electric and hydraulic infinitely variable transmissions, the mechanical infinitely variable transmissions (variators) are widely used.

The use of infinitely variable transmissions in the drives of machines allows to increase their technical and economic indicators [1-5].

These include pulsed variable-speed drives, which are compact in terms of unit power. They have a wide range of control of frequency-amplitude characteristics, they can be automatic and combine the functions of the reduction drive [6-11].

The main characteristics that determine the performance of the pulsed variable-speed drive are gear ratio, efficiency, reliability of the free-wheel mechanisms [12-18].

The efficiency of the pulsed variable-speed drive is an integral indicator which depends on a number of structural, technological, and operational factors.

These factors primarily include:

- constructive arrangement of the transforming mechanism of the variator (coaxial gear and lever, noncoaxial lever, non-coaxial cam, etc.);

- type of free-wheel mechanism (friction, nonfriction, combined) acting as a rectifier for mechanical vibrations;

- range of gear ratio;

- design of the control mechanism;

- value of the transmitted load.
Taking into complete account of the influence of that factors by theoretical methods is a very difficult task. Currently, when using theoretical methods to assess the performance of pulsed variable-speed drives, two approaches are used most commonly.

The first approach is to use mathematical models with a number of significant reductions and assumptions. For example, in $[8,12]$, the performance of pulsed variable-speed drives is estimated on the basis of systems of Lagrange differential equations of the second kind.

The systems of equations and mathematical formulas obtained by the author describe only certain characteristics of the pulsed variable-speed drive and are difficult for practical use.

The second approach involves an indirect assessment, when the performance of the pulsed variable-speed drives is determined by the reliability of the most loaded elements. Usually such elements are the free-wheel mechanisms.

Thus, in [9], the reliability of several types of freewheel mechanisms was determined and analyzed by analytical methods of the material resistance and the reliability theory. The performance of the pulsed variable-speed drive as a whole was evaluated by the results obtained.

Such approaches require experimental confirmation of the results obtained. Therefore, to estimate its working capacity, a calculation and experimental method was chosen. 


\section{Experimental setup}

To research the performance of the pulsed variablespeed drive, a special stand was developed (Fig. 1).

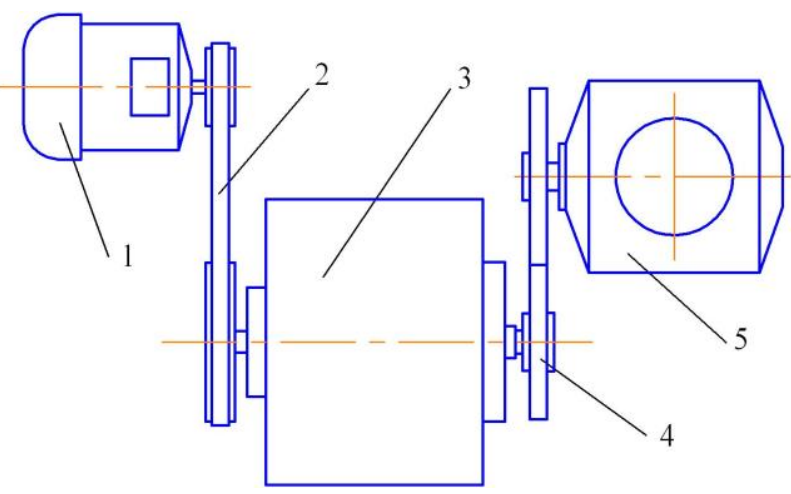

Fig. 1. The kinematic scheme of the experimental stand for the evaluiation of the pulsed variable-speed drive: 1 - electric motor, 2 - V-belt drive, 3 - pulsed variable-speed drive, 4 gear drive 5 - brake.

The stand consists of an electric motor (132M4 IE2/EFF1, $7.5 \mathrm{~kW}$, nominal frequency $1450 \mathrm{~min}^{-1}$ ) connected by a V-belt drive (gear ratio $i=1.61$ ) to the drive shaft of the pulsed variable-speed drive, the driven shaft of which (gear ratio $i=3.55$ ) is connected to the electromagnetic powder brake of PT-100M type.

The pulsed variable-speed drive has the following technical characteristics: transmitted power $P=7.5 \mathrm{~kW}$; maximum torque at the output shaft $T=3000 \mathrm{~N} \cdot \mathrm{m}$; the range of variation of the output shaft speed $n=0 \ldots 45$ $\min ^{-1}$; dimensions $L \times B \times H=660 \times 670 \times 670 \mathrm{~mm}$.

The pulsed variable-speed drive was made according to a coaxial gear and lever scheme (Fig.2).

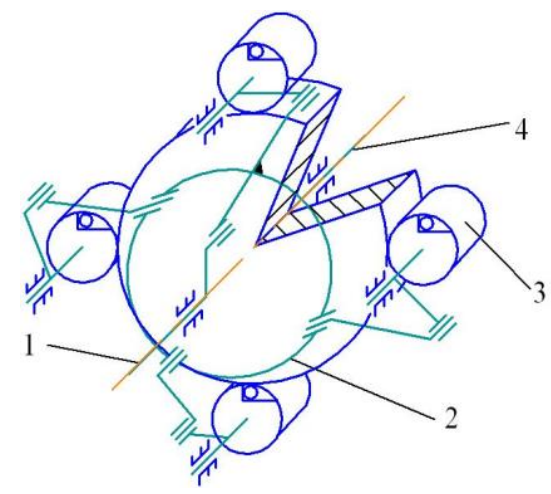

Fig. 2. Kinematic scheme of the pulsed variable-speed drive: 1 - drive shaft, 2 - transforming mechanism, 3 - free-wheel mechanism, 4 - driven shaft.

The eccentric free-wheel mechanisms of the nonfriction type which have a high load capacity were used as transformers of mechanical impulses (Fig.3 and Table1).

The main advantages of eccentric freewheel mechanisms are: the compactness of the structure per unit of transmitted load; relatively low requirements to the accuracy of manufacturing and assembly of the mechanism elements; low friction losses during freewheeling period; slight effect of wear on performance [15].

The eccentric free-wheel mechanisms had the following design parameters: outer cage diameter $D=120 \mathrm{~mm}$, wedging angle $\alpha=12^{\circ} \pm 30^{\prime}$.

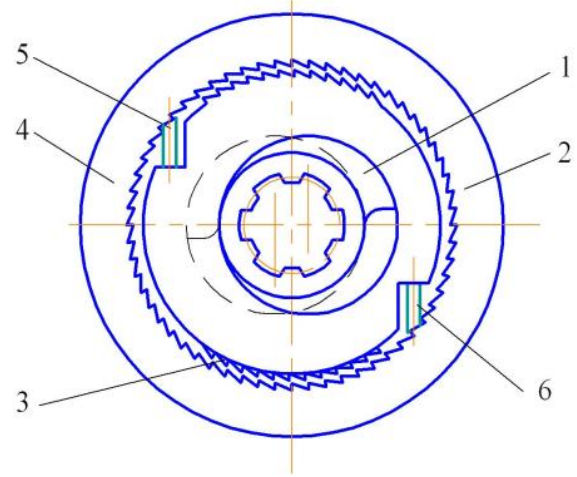

Fig. 3. The eccentric free-wheel mechanism of the nonfriction type: 1 - double-sided eccentric, 2 and 3 - eccentric rings, 4 - outer cage, 5 and 6 - partial braking.

Before the experimental measurements, the pulsed variable-speed drive passed the operating time for 50 hours at a reduced load, which was $10 \%$ of the maximum.

During the tests, the SAE 30 oil was used, the turnon frequency of eccentric free-wheel mechanisms was $15 \mathrm{~Hz}$.

Table 1. Parameters of free-wheel mechanisms.

\begin{tabular}{|c|c|c|c|}
\hline $\begin{array}{c}\text { Series } \\
\text { No }\end{array}$ & Module $m, \mathrm{~mm}$ & Material & $\begin{array}{c}\text { Turn-on cycles } \\
N_{\mathrm{m}}\end{array}$ \\
\hline 1 & 0.50 & $100 \mathrm{Cr} 6$ & $2.10 \cdot 10^{6}$ \\
\hline 2 & 0.75 & $100 \mathrm{Cr} 6$ & $2.90 \cdot 10^{6}$ \\
\hline 3 & 0.75 & $14 \mathrm{NiCr} 10$ & $1.50 \cdot 10^{6}$ \\
\hline 4 & 0.75 & $20 \mathrm{MnCr} 5 \mathrm{G}$ & $1.65 \cdot 10^{6}$ \\
\hline
\end{tabular}

\section{Experimental research of the performance of the pulsed variable- speed drive}

\subsection{Research of the reliability of the pulsed variable-speed drive}

The free-wheel mechanisms are the most loaded elements in the loading pattern of the pulsed variablespeed drive.

When the pulsed variable-speed drive is in operation, they function under high switching frequency reaching $50 \mathrm{~Hz}$, under significant transmitted torque, and dynamic loads. Their reliability influences the performance of the variable-speed drive as a whole.

The free-wheel mechanisms are recoverable products and, when tested, the sequential method of control is most effective $[19,20]$. 
The initial data during such tests are: manufacturer's risk $-\alpha$; customer's risk $-\beta$; rejection value of the mean time between failures $-T_{\beta}$; acceptance value of mean time between failures $-T_{\alpha}$; lower bound of confidence interval of mean time between failures $-T_{\mathrm{m}}$. According to the recommendation we took $\alpha=\beta=0.1$ and $T_{\alpha}=2 T_{\beta}=2 T_{\mathrm{m}}$.

Since the turn-on frequency of free-wheel mechanisms for the same period of time can be different, when studying their reliability it is convenient to use not the operating time, but the corresponding number of turn-on cycles $-N_{\alpha}=2 N_{\beta}=2 N_{\mathrm{m}}$.

The number of turn-on cycles $N_{\mathrm{m}}$ (Table 1) corresponding to the lower bound of confidence interval of time between failures was accepted according to the results of experimental studies [21].

To determine the allowable number of failures $[\omega]$ the graphs were built according to dependencies (1) and (2), which are lines of conformity and nonconformity of the actual given level of reliability:

$$
\begin{aligned}
& {[\omega]=a\left(\frac{N_{s}}{N_{\alpha}}+\frac{\ln [\beta /(1-\alpha)]}{\left(N_{\alpha} / N_{\beta}\right)-1}\right) ;} \\
& {[\omega]=a \frac{N_{s}}{N_{\alpha}}+\frac{\ln [(1-\beta) / \alpha]}{\ln \left[N_{\alpha} / N_{\beta}\right]} .}
\end{aligned}
$$

Here: $a=\frac{\left(N_{\alpha} / N_{\beta}\right)-1}{\ln \left(N_{\alpha} / N_{\beta}\right)}, N_{s}-$ total number of turnon cycles.

The dependencies (1)-(2) are received according to the source [22] with use of function of the maximum credibility.

Researches of the pulsed variable-speed drive showed the following results (Fig. 4 and Table 2).

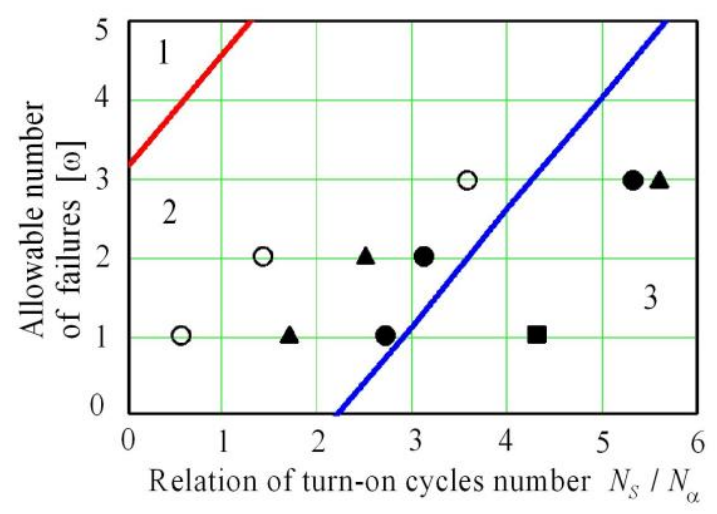

Fig. 4. The results of the evaluation of the performance of free-wheel mechanisms: 1 - zone of nonconformity, 2 - zone of uncertainty, 3 - zone of conformity; ○ - series No.1, series No.2, $\bullet-$ series No.3, $\boldsymbol{\Delta}$ - series No.4.

If the relation $N_{\mathrm{s}} / N_{\alpha}$ is above the nonconformity line (zone of nonconformity) then the test results are considered negative. If it is below the conformity line (zone of conformity) the results are positive. If it is between the conformity and nonconformity lines (zone of uncertainty) the tests continue.

It was accepted that the number of failures of the free-wheel mechanisms for the entire period of testing may be no more than three.

The testing of the pulsed variable-speed drive was carried out at a load on the driven shaft equal to 25,50 , 75 and $100 \%$ of its maximum value. The operating time at the maximum load value was $65 \ldots 80 \%$ of the total test time.

\begin{tabular}{|c|c|c|c|c|}
\hline \multirow{2}{*}{$\begin{array}{c}\text { Series } \\
\text { No }\end{array}$} & \multicolumn{3}{|c|}{ Failure parameters } & \multirow{2}{*}{ Test result } \\
\hline & Failure & $\begin{array}{c}N_{\mathrm{s}} \\
\text { turnons. }\end{array}$ & Zone & \\
\hline \multirow{3}{*}{1} & $1^{\text {st }}$ & $2.31 \cdot 10^{6}$ & uncertainty & \multirow{3}{*}{ negative } \\
\hline & $2^{\text {nd }}$ & $5.88 \cdot 10^{6}$ & uncertainty & \\
\hline & $3^{\text {rd }}$ & $15.0 \cdot 10^{6}$ & uncertainty & \\
\hline 2 & $1^{\text {st }}$ & $25.0 \cdot 10^{6}$ & conformity & positive \\
\hline \multirow{3}{*}{3} & $1^{\text {st }}$ & $8.90 \cdot 10^{6}$ & uncertainty & \multirow{3}{*}{$\begin{array}{l}\text { conditionally } \\
\text { positive }\end{array}$} \\
\hline & $2^{\text {nd }}$ & $18.0 \cdot 10^{6}$ & uncertainty & \\
\hline & $3^{\text {rd }}$ & $10.2 \cdot 10^{6}$ & conformity & \\
\hline \multirow{3}{*}{4} & $1^{\text {st }}$ & $5.10 \cdot 10^{6}$ & uncertainty & \multirow{3}{*}{$\begin{array}{l}\text { conditionally } \\
\text { positive }\end{array}$} \\
\hline & $2^{\text {nd }}$ & $7.50 \cdot 10^{6}$ & uncertainty & \\
\hline & $3^{\text {rd }}$ & $17.0 \cdot 10^{6}$ & conformity & \\
\hline
\end{tabular}

Table 2. Parameters of free-wheel mechanisms failures.

The testing of the pulsed variable-speed drive were carried out with eccentric free-wheel mechanisms of series No. 1 for 277 hours, series No.2 - 462 hours, series No. 3 - 333 hours, series No. 4 - 314 hours.

When using graphs, it should be borne in mind that for different free-wheel mechanisms the value $N_{\alpha}$ is also different. Therefore, the same value of the relation $N_{\mathrm{s}} / N_{\alpha}$ will correspond to different number of turn-on cycles.

Despite the fact that the last failures during the operation of the pulsed variable-speed drive with eccentric free-wheel mechanisms No.3 and 4 occurred in the zone of conformity, the tests can only be considered conditionally positive, since the first two failures occurred in the zone of uncertainty.

\subsection{Research of the kinematic characteristics of the pulsed variable-speed drive}

The most important parameter determining the kinematic characteristics of the variable-speed drive is the stability 
and the value of its gear ratio during load transfer $i_{T}[1$, $5,23,24]$.

For example, free-wheel roller mechanisms have low torsional rigidity, what is the disadvantage that affects the stability of the kinematic characteristics of the pulsed variable-speed drive [25-27].

Studies of the pulsed variable-speed drives have shown that the slip of the free-wheel roller mechanisms can lead to an increase in its gear ratio by $40 \ldots .44 .5 \%$ [15].

The eccentric free-wheel mechanism of the nonfriction type, in comparison with roller mechanisms, have higher torsional rigidity and can provide greater stability of the kinematic characteristics of the pulsed variable-speed drive with increasing load.

During the experiment, the gear ratio under load $i_{T}$ was taken as the factor under research. The initial gear ratio without load $i_{H}$ and the torque $T$ on the driven shaft were taken as independent factors.

According to the results of experimental studies of eccentric free-wheel mechanisms of non-friction type, they have constant torsional rigidity, which can be described by a linear relationship [20].

Therefore, the design of the experiment and the creation of a mathematical model describing the change in the gear ratio of the pulsed variable-speed drive were carried out on the basis of first-order designs of type $2^{2}$ $[20,28]$.

The independent parameters of the model were ranged on two levels: $i_{H}=20$ and 180; $T=250$ and 2750 $\mathrm{N} \cdot \mathrm{m}$. The measurements were carried out at the points of the experimental design and additional points at $i_{H}=100$.

The dispersion of experimental results can be considered homogeneous, since Cochran's criterion values [28] for the results of all experiments are less than the critical ones.

Analysis of experimental results (Fig. 5) shows that in the load range $T=250 \ldots 2750 \mathrm{~N} \cdot \mathrm{m}$ there $\cdot$ is a linear increase in the gear ratio by $1.0 \ldots 9.9 \%$.

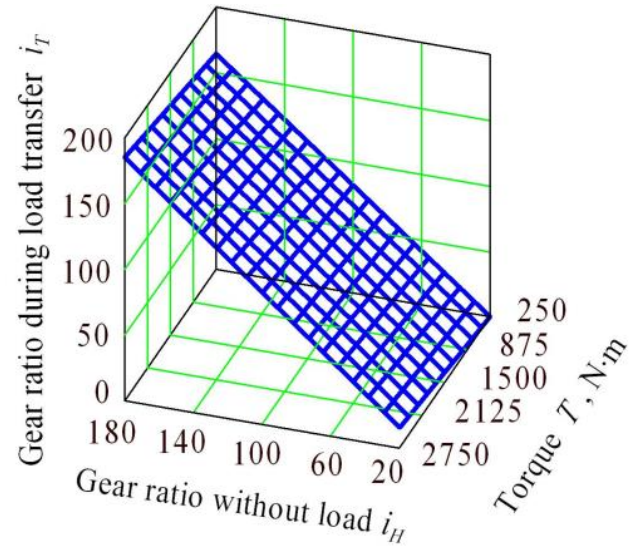

Fig. 5. The change in the kinematic characteristics of the pulsed variable-speed drive: $1-i_{H}=180,2-i_{H}=100,3-$ $i_{H}=20$.
The increase in the gear ratio can be explained by the fact that with an increase in the load, the runout of the free-wheel mechanisms decreases or is completely absent, and the reversible deformation of their members occurs.

An empirical dependence that characterizes the change in the kinematic characteristics of the pulsed variable-speed drive is obtained

$$
i_{T}=-4.37 \cdot 10^{-1}+i_{H}-4.50 \cdot 10^{-5} T+2.82 \cdot 10^{-5} i_{H} T .
$$

For the obtained dependence (3), the relative error between the theoretical and experimental values for most points is $0.88 \ldots 3.90 \%$ and reaches $6.16 \ldots 7.46 \%$ for only three points.

\subsection{Research of the efficiency coefficient of the pulsed variable-speed drive}

Efficiency coefficient is an important technical characteristic that determines the performance of the pulsed variable-speed drive.

As is known, when a load is transferred by the variable-speed drive, a nonlinear change in efficiency in a wide range occurs $[2,8,29]$.

Therefore, the design of the experiment and the creation of a mathematical model describing the change in the efficiency coefficient were carried out on the basis of second-order designs of $3^{2}$ type $[19,28]$.

The independent parameters of the linear model were ranged on three levels: $i_{H}=20,100$ and 180; $T=250$, 1500 and $2750 \mathrm{~N} \cdot \mathrm{m}$. The measurements were carried out at the points of the experimental design and additional points.

In all the results of experiments the values of the Cochran's criterion are less than the critical ones, which confirms the homogeneity of the experimental results [28].

Analysis of experimental results (Fig. 6) shows that in the load range $T=200 \ldots 2800 \mathrm{~N} \cdot \mathrm{m} \cdot$, the increase $\eta$ is non-linear and is $1.8 \ldots 2.6$ times. With an increase $i_{H}$ in the range from 20 to 180 , the efficiency coefficient increases by $1.13 \ldots 1.64$ times.

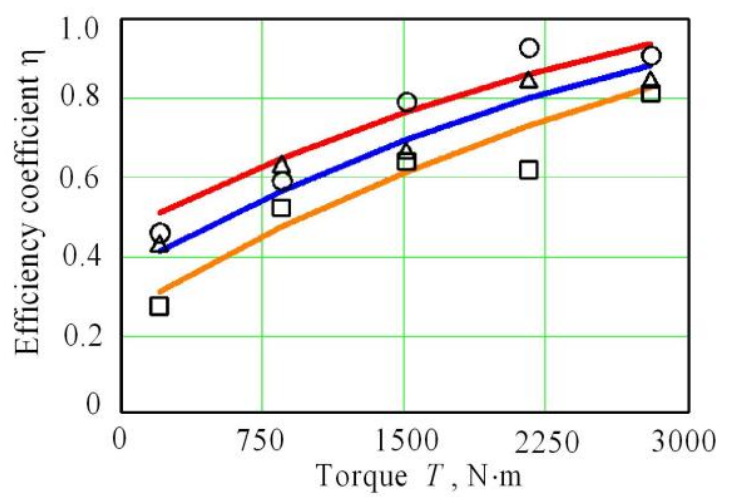

Fig. 6. Change in the efficiency coefficient of the pulsed variable-speed drive: $\square-i_{H}=20, \Delta-i_{H}=100$, $\circ-$ $i_{H}=180$. 
An empirical formula for determining the efficiency coefficient is obtained

$$
\begin{aligned}
& \eta=0.483+2,43 \cdot 10^{-4} T-0.50 \cdot 10^{-2} i_{H}- \\
& 2.78 \cdot 10^{-8} T^{2}-4.15 \cdot 10^{-6} i_{H}^{2}+8.85 \cdot 10^{-7} T_{H}
\end{aligned} .
$$

For the obtained dependence (4), the relative error between the theoretical and experimental values for all points of the experimental design is $1.3 \ldots 12.5 \%$, and for the additional points $-5.2 \ldots 16.4 \%$.

\section{Conclusion}

It was established that the reliability of the eccentric free-wheel mechanisms made of $14 \mathrm{NiCr} 10$ and $20 \mathrm{MnCr} 5 \mathrm{G}$ steel is not ensured under impulsed loading conditions. The required reliability is guaranteed when making mechanisms of $100 \mathrm{Cr} 6$ steel with hardness not lower than $\mathrm{HRC}_{\ni} 58 \ldots 62$ with a module of at least 0.75 $\mathrm{mm}$.

The obtained dependences (3)-(4) adequately describe the yield surfaces, since the Fisher's criterion values [26] for them are less than the critical ones.

When operating the pulsed variable-speed drive, it is advisable to provide large values of the load with average values of the gear ratio, which allows to obtain optimal working capacity characteristics.

\section{References}

1. E. Ince, M.A. Guler, J. of Mech. Des., Transact. of the ASME. 141(5), 054501 (2019)

2. F. Bottiglione, S. De Pinto, G. Mantriota, Mech. and Mach. Theory. 74, 285-298 (2014)

3. R. Alò, F. Bottiglione, G. Mantriota, Mech. Based Des. of Structur. and Mach. 46(3), 333-346 (2018)

4. L. Tong, S. Wang, D. Wang Proceedings of the 2011 2nd International Conference on Digital Manufacturing and Automation, ICDMA 2011. 6052006, 280-284 (2011)

5. J. Maten, B. Anderson Continuously Variable Transmission (CVT) (SAE, 2006)

6. F.J. Morales, F.G. Benitez, Mech. and Mach. Theory. 134, 197-212 (2019)

7. E. Tsuchiya, E. Shamoto, Mech. and Mach. Theory. 118, 265-282 (2017)

8. S. Aliukov, A. Keller, A. Alyukov, Lect. Not. in Eng. and Comp. Science. 2, 702-706 (2017)

9. V.P. Bondaletov, V.I. Medvedev, A.V. Petrov, Rus. Eng. Research. 30(10), 995-998 (2010)

10. G. Centeno, F. Morales, F.B. Perez, F.G. Benitez, J. of Mech. Des., Transact. of the ASME. 132(5), 051004 (2010)

11. J. Sun, W. Fu, H. Lei, E. Tian, Z. Liu, Chin. J. of Mech. Eng. 25(6) 1138-1143 (2012)

12. S.V. Alyukov, Rus. Eng. Research. 34(7), 436-439 (2014)
13. K.C. Liu, Z.X. Zheng Proceedings of the International Conference on Manufacturing Engineering and Intelligent Materials, ICMEIM 2015. 1-6 (2015)

14. F.G. Benitez, J.M. Madrigal, J.M. del Castillo, J. of Mech. Des., Transact. of the ASME. 126(4), 673682 (2004)

15. O.V. Sharkov, S.I. Koryagin, Rus. Eng. Research. 37(1), 9-12 (2017)

16. J. Sun, E. Tian, H. Lei, Z. Liu, W. Fu, Advanc. Scienc. Letters. 19(6), 1705-1708 (2013)

17. V.P. Bondaletov, T.E. Bykova, Rus. Eng. Research. 29(2), 119-121 (2009)

18. F.J. Morales, F.G. Benitez, SAE Technical Papers. 1, (2014)

19. S. Woo Reliability Design of Mechanical Systems: A Guide for Mechanical and Civil Engineers (Springer, 2017)

20. L.J. Gullo, J. Dixon Design for Safety (John Wiley \& Sons, 2017)

21. O.V. Sharkov, S.I. Koryagin, N.L. Velikanov, Matec Web of Confer. 224, 02089 (2018)

22. K.C. Kapur, L.R. Lamberson Reliability in Engineering Design (Wiley India Pvt., 2009)

23. J.-P. Gauthier, P. Micheau, Control Eng. Pract. 20(6), 569-574 (2012)

24. C.A. Moore, M.A. Peshkin, J.E. Colgate Proceedings 1999 IEEE International Conference on Robotics and Automation. 4, 3249-3254 (1999)

25. W.C. Orthwein Clutches and brakes: design and selection (Marcel Dekker, 2004)

26. K. Liu, E. Bamba, Tribol. Intern. 38(2),187-194 (2005)

27. H. Ding, J. of Sound and Vibrat. 353, 308-326 (2015)

28. A. Dean, D. Voss, D. Draguljić Design and Analysis of Experiments (Springer, 2017)

29. J.P. Newall, S. Cowperthwaite, M. Hough, A.P. Lee, Tribol. and Interf. Eng. Series. 48, 245-255 (2005) 